\title{
Avaliação da diversidade arbórea das ilhas do rio Paraguai na região de Cáceres, Pantanal Matogrossense, Brasil
}

Solange Kimie Ikeda Castrillon ${ }^{1,4}$, Carolina Joana da Silva ${ }^{1,2}$, José Ricardo Castrillon Fernandez ${ }^{3}$ e Andrea Kyoko Ikeda ${ }^{1}$

Recebido em 31/03/2010. Aceito em 30/06/2011

\section{RESUMO}

(Avaliação da diversidade arbórea das ilhas do rio Paraguai na região de Cáceres, Pantanal Matogrossense, Brasil). A diversidade de plantas está associada à heterogeneidade de habitats, à ampla distribuição de espécies, ao pulso de inundação que podem estar sendo controlados pela dinâmica fluvial e diferenças na origem geomorfológica. Este estudo avaliou a diversidade da vegetação arbórea em seis ilhas do rio Paraguai, entre Cáceres e a Estação Ecológica de Taiamã, Pantanal Matogrossense. Foram comparadas ilhas originárias de dois processos geomorfológicos: a partir do rompimento do colo do meandro e de sedimentação. Foram estabelecidas 22 parcelas $(10 \times 20 \mathrm{~m})$ por ilha, distantes $50 \mathrm{~m}$ entre si, onde foram amostradas todas as árvores com DAP $\geq 5 \mathrm{~cm}$. Foram alocadas 10 parcelas na parte central e 12 nas bordas das ilhas. O cluster construído a partir do coeficiente de Sorensen resultou em dendrogramas, baseados em ligações simples e distancia euclidiana dos índices de similaridade, onde se observam as hierarquias entre os grupos formados, considerando parcelas localizadas no centro e borda das ilhas e entre ilhas. Foram registradas 40 espécies pertencentes a 34 gêneros e 21 famílias. Os Índices de Diversidade de Shannon-Weaver variaram de H’ 0,91 a 2,72. Houve diferença na composição florística das ilhas originárias do rompimento do colo de meandro e partir de sedimentação. Houve diferença na composição florística do centro e borda nas ilhas formadas por rompimento do colo de meandro.

Palavras-chave: pantanal, ilhas, vegetação arbórea, origem geomorfológica, pulso de inundação

\begin{abstract}
(Assessment of tree diversity on the islands of the Paraguay River, in the Caceres region, Pantanal, Brazil). Plant diversity on islands is associated with habitat heterogeneity, the distribution of a species, the flood pulse that may be influenced by fluvial dynamics and differences in geomorphologic origin. This study assessed the diversity of trees on six islands of the Paraguay River, between Caceres and Taimã Ecological Station, in the Pantanal, Brazil. Islands created by two geomorphologic processes were compared: sedimentation and islands formed when the necks of meanders erode. All of the trees with $\mathrm{DBH} \geq 5 \mathrm{~cm}$ were sampled from $22(10 \mathrm{~m} \times 20$ $\mathrm{m}$ ) plots (per island), which were $50 \mathrm{~m}$ from each other. Ten plots were allocated in the central parts and 12 on the edges of the islands in areas where there was erosion and sediment deposition. The cluster constructed from the Sorensen coefficient resulted in dendrograms based on single bonds and Euclidean distance of similarity indexes, where hierarchies were observed among the groups when considering the plots located in the center and on the edge of the islands, and between islands. Forty species belonging to 34 genera and 21 families were recorded. The Shannon-Weaver diversity indexes ranged from H' 1.08 to 2.77 . There was a difference in the floristic composition on the islands that were formed when necks of meanders eroded compared to those formed by sedimentation. There was a difference in the floristic composition when comparing the center and edge of islands formed when necks of meanders eroded.
\end{abstract}

Key words: Pantanal, islands, arboreal vegetation, geomorphologic origin, flood pulse

\footnotetext{
${ }^{1}$ Universidade do Estado de Mato Grosso, Departamento de Ciências Biológicas, Cáceres, MT, Brasil

${ }^{2}$ Universidade Federal de São Carlos, Programa de Pós Graduação em Ecologia e Recursos Naturais, São Carlos, SP Brasil

${ }^{3}$ Instituto Tecnológico Federal de Mato Grosso, Cáceres, MT, Brasil

${ }^{4}$ Autor para correspondência: ikedacastrillon@gmail.com
} 


\section{Introdução}

Diversos estudos têm avaliado os mecanismos que determinam as diferentes paisagens no Pantanal, tais como mudanças paleoclimáticas (Ab’Saber 1988), pulso de inundação (Junk et al. 1989), dinâmica fluvial e adaptação de espécies (Adámoli \& Pott 1999). No Pantanal, localmente, as comunidades vegetais distribuem-se segundo a influência dos gradientes de inundação e no plano temporal, mudanças no leito fluvial iniciam processos sucessionais, que se manifestam na dinâmica da vegetação arbórea (Adámoli \& Pott 1999).

A biota no sistema de rios alagáveis é controlada pelo pulso de cheias (Junk et al.1989). É provável que espécies arbóreas desempenhem um papel importante na estabilização do solo e mudanças no grau de hidromorfia, gerando condições favoráveis ao estabelecimento de novas espécies arbóreas, resultando em gradual avanço de formações florestais sobre as áreas mais abertas do Pantanal. Diversos fatores podem estar controlando a expansão das formações vegetais no pantanal, dentre eles, a inundação tem sido a mais estudada (Prance \& Schaler 1982; Adámoli 1982; Nascimento \& Nunes da Cunha 1989; Adámoli \& Pott 1999; Damasceno Júnior et al. 1999; Pott \& Adámoli 1999; Nunes da Cunha \& Junk 1999; Nunes da Cunha \& Junk 2001; Damasceno-Júnior 2004; Damasceno Júnior et al. 2005; Arieira \& Nunes da Cunha 2006).

Outro fator sugerido por Prance \& Schaler (1982) e Hamilton et al. (1996), é o impacto humano na vegetação do Pantanal com a introdução do gado e o uso do fogo durante os últimos 200 anos. Os autores acreditam que as atividades humanas têm influenciado a natureza e a distribuição da vegetação no Pantanal. Com relação à presença humana, existem citações sobre os "aterros dos bugres" que são ilhas para a permanência em época de cheia utilizada por grupos indígenas que ocuparam o Pantanal antes da colonização européia. Estes aterros são um dos poucos exemplos de aproveitamento sustentável em sistemas complexos como áreas alagáveis (Junk \& Da Silva 1999).

As ilhas sempre foram locais de importantes pesquisas acerca da biodiversidade. A partir das ilhas oceânicas surgiram teorias como "A origem das espécies" em 1859 e a teoria de Biogeografia de Ilhas (MacArthur \& Wilson 1967) que desencadeou estudos sobre o efeito área, que preconiza que quanto maior a ilha, maior o número de espécies presentes e mais lenta a extinção local, com o inverso ocorrendo em ilhas pequenas onde os recursos são mais finitos.

A riqueza de espécies em uma região é o resultado de muitos processos agindo através do espaço e tempo. A quantificação de outras variáveis, além da área, é fundamental para avaliação da diversidade e ao mesmo tempo tem alto poder explicativo (como idade ilha, distância, produtividade, energia e heterogeneidade ambiental), sendo necessária para construir uma previsão mais científica da riqueza de espécies em sistemas de ilhas (Triantis et al. 2008). Por exemplo, a heterogeneidade espacial de hidroperiodos das zonas úmidas temporárias tem um forte impacto sobre a riqueza de espécies de plantas vasculares, enquanto área de habitat não têm um impacto significativo (Brose 2001).

A margem do rio é um tipo de borda, constitui uma variável complexa, englobando maior umidade do solo, exposição ao sol e suscetibilidade a cheias ocasionais (Souza et al. 2003). Muitas vezes espécies podem estar distribuídas nas margens dos rios condicionadas principalmente pela maior luminosidade propiciada pela abertura do rio (Oliveira Filho et al. 1994).

No rio Paraguai, Pantanal de Cáceres, as ilhas ocorrem ao longo de setores mais retilíneos, tendo se originado, a partir do canal por barras de areia, afloramentos rochosos e de meandro em evolução. Em meandros e setores de transição a migração de braços de canal e subseqüentes rompimentos formaram ilhas com matas alagáveis (Wantzen et al. 2005). Entre a área urbana do município de Cáceres e a Estação Ecológica de Taiamã no rio Paraguai, Souza et al. (2007) verificaram ilhas formadas a partir do rompimento do colo do meandro e ilhas formadas pelo processo de sedimentação.

Este estudo avaliou a diversidade da vegetação arbórea em seis ilhas do rio Paraguai, originárias do rompimento do colo do meandro e do processo de sedimentação através das questões: Qual a composição florística e estrutura da vegetação arbórea? Existe similaridade da flora entre as ilhas? Há diferença na riqueza? Existe diferença na composição florística da borda e centro das ilhas? A distância entre as ilhas influencia a composição?

\section{Material e métodos}

O Pantanal é a mais espessa bacia de sedimentação quaternária do País. O pacote detrítico em seu interior detém de 400 a 500m de sedimentos acumulados. Está situado entre três grandes domínios morfoclimáticos e fitogeográficos sulamericanos, dos Cerrados, do Chaco e da Pré-Amazônia, funcionando como uma imensa depressão aluvial tampão e ao mesmo tempo como receptáculo de componentes bióticos provenientes das áreas circunvizinhas (Ab `Saber 2006).

A principal área de influência amazônica dentro do Pantanal, ligada ao vale do rio Paraguai, apresenta um interesse adicional, uma vez que é a única via possível de conexão florística atual, entre a Floresta Amazônica e as Florestas Meridionais. O rio Paraguai e os seus afluentes Sepotuba, Cabaçal e Jauru drenam áreas parcialmente cobertas por florestas de linhagem amazônica (Adámoli 1986). Na região da foz destes rios, encontra-se o Pantanal de Cáceres, próximo à área de estudo.

A vegetação desta região é classificada como Floresta Estacional Semi-Decidual Aluvial, uma formação encontrada com grande freqüência na depressão pantaneira, sempre margeando os rios da bacia do rio Paraguai, podendo ser regionalmente reconhecida como mata de galeria, mata ciliar, ripária e florestas inundáveis. Caracteriza-se por uma 
formação florestal ribeirinha que ocupa as acumulações fluviais quartenárias, sendo sua estrutura semelhante à floresta ciliar de outros rios, diferindo apenas florísticamente porque aparecem espécies de plantas vicariantes da Amazônia Ocidental (sensu Veloso et al. 1991).

O Pantanal de Cáceres se estende do sul da cidade de Cáceres - MT até a Ilha do Caracará. A princípio, comprimido entre a depressão do Alto Paraguai e a Província Serrana, é limitado a oeste, pela fronteira com a Bolívia, a leste, pelo curso do rio Paraguai, que descreve um arco voltado para o ocidente até a Morraria da Ïnsua, já nos limites daquele país (PCBAP 1997).

O clima do Pantanal de Cáceres, de acordo com a classificação de Koppen é do tipo Aw (quente e úmido), a precipitação anual de $1500 \mathrm{~mm}$, com maior intensidade nos meses de janeiro, fevereiro e março. As temperaturas médias anuais das máximas e mínimas são em torno de $32^{\circ} \mathrm{C} \mathrm{e} 20^{\circ}$ $\mathrm{C}$, respectivamente. A alternância de estações chuvosas e secas define o clima de caráter estacional.

Os solos da área de estudo predominam o Gleissolo Eutrófico, com argila de alta capacidade de troca de cátions (Soares et al. 2006). As ilhas são submetidas à inundação anual por um período de aproximadamente 6 meses, normalmente entre os meses de novembro a abril (IkedaCastrillon 2011).

A unidade geomorfológica, Planícies e Pantanais Mato-grossenses, é caracterizada por deposição recente de sedimentos da Formação Pantanal, formada por solos hidromórficos em sua maioria e possui forte tendência para inundações periódicas e prolongadas. A Planície Fluvial é uma feição relacionada aos rios, principalmente o Paraguai e afluentes, estão modeladas em depósitos aluviais holocentricos e caracterizada por apresentarem diques marginais, ilhas e lagoas (Franco \& Pinheiro 1982).

Souza (2007) em seu trabalho, observou as mudanças espaço-temporais do corredor fluvial, formado pela planície marginal (baías, lagoas, vazantes e ilhas fluviais) e da calha do rio Paraguai em três compartimentos entre área urbana do município de Cáceres e a Estação Ecológica de Taiamã. No primeiro compartimento na região mais próxima a cidade de Cáceres o rio possui padrão meandrante, dinâmica caracterizada pela erosão acelerada e deposição de sedimentos na calha e na planície de inundação, com presença de ilhas originárias do rompimento do colo do meandro. Em seguida o canal diminui a sinuosidade, tornando-se retilíneo e apenas retornando ao padrão meandrante no terceiro compartimento próximo a Taiamã, nestes últimos compartimentos verificam-se ilhas originárias do processo de sedimentação.

Foram mapeadas e sorteadas para estudo seis ilhas no rio Paraguai entre a cidade de Cáceres-MT a Estação Ecológica de Taiamã, no Pantanal Matogrossense.As seis ilhas estão localizadas entre as coordenadas $16^{\circ} 08^{\prime} 05,3^{\prime \prime}$ S e $57^{\circ} 43^{\prime} 49,3^{\prime \prime}$ $\mathrm{W}$ e $16^{\circ} 48^{\prime} 57,4^{\prime \prime} \mathrm{S}$ e $57^{\circ} 37^{\prime} 46,9^{\prime} \mathrm{W}$. As três primeiras (1, 2 e 3), estão localizadas mais próximas à Cáceres, são ilhas formadas a partir do rompimento do colo meandro do rio e possuem as seguintes áreas respectivamente: 155,27, 199,23 e 74,36 ha e as ilhas formadas por sedimentação $(4,5$ e 6$)$ com áreas: 13,80, 25,26 e 15, 53 ha e estão mais próximas da Estação Ecológica de Taiamã (Fig. 1).

A localização das parcelas teve o objetivo de amostrar diferenças entre locais. Foram estabelecidas 22 parcelas (10 $\mathrm{x} 20 \mathrm{~m}$ ) por ilha. Foram alocadas 10 no interior (centro) e 12 na borda da ilha. As parcelas de borda foram alocadas de três em três, próximas as margens do rio no sentido norte/ sul e leste/oeste distantes 50 metros entre si e considerando uma borda de $100 \mathrm{~m}$. A partir do centro das ilhas foram alocadas quatro parcelas no sentido norte/sul e seis parcelas em um ângulo de $240^{\circ} \mathrm{em}$ relação ao centro, três para cada lado, distantes 50 metros entre si (Fig.2). O total da área amostral foi de 2,64 ha.

Foram levantados indivíduos com DAP (Diâmetro a Altura do Peito) $\geq 5 \mathrm{~cm}$ e altura $\geq 3 \mathrm{~m}$. Para a estrutura e composição da comunidade arbórea das ilhas foram utilizados parâmetros fitossociológicos, com suas fórmulas, segundo proposição de Muller-Dombois \& Ellenberg (1974), calculados através do programa o programa Mata Nativa 2.0 (CIENTEC 2006).

A classificação das espécies segundo as famílias botânicas seguiu o sistema do "Angiosperm Phylogeny Group III" (APG III 2009). O material botânico coletado foi identificado com auxílio de bibliografia especializada e por comparação com o material do Herbário do Pantanal (HPAN) da Universidade do Estado de Mato Grosso, da Universidade Federal de Mato Grosso do Sul e apoio técnico do Herbário da Universidade Federal de Mato Grosso. Posteriormente este material foi depositado no HPAN, com duplicatas encaminhadas aos Herbários da Universidade Federal de Mato Grosso do Sul e Universidade Federal de Mato Grosso.

Para inquirir e comparar a diversidade e a similaridade florística entre as ilhas do rio Paraguai, foi utilizado o índice de diversidade de Shannon e o índice de similaridade de SØrensen (Ss), este índice, baseado na presença e ausência de espécies, enfatiza as espécies comuns às áreas, dando peso maior para estas espécies (Kent \& Coker 1996). O intervalo de confiança do índice de Shannon foi calculado pelo método de Jackknife (Heltshe \& Forrester 1983).

A análise da similaridade foi feita através da classificação aglomerativa por UPGMA (Unweighted Pair Groups Method using Arithmetic Averages) (James \& McCulloch 1990). A classificação por UPGMA resultou em dendrogramas, baseados em ligações simples e distancia euclidiana dos índices de similaridade, onde se observam as hierarquias entre os grupos formados, considerando as ilhas e parcelas localizadas no centro e borda.

Para avaliar a riqueza entre as ilhas de diferentes origens foi utilizada ANOVA (dados log tranformados) calculada pelo programa BioEstat 5.0 (Ayres et al. 2003). A construção dos gráficos foi realizada por meio do software Microsoft Excel. 


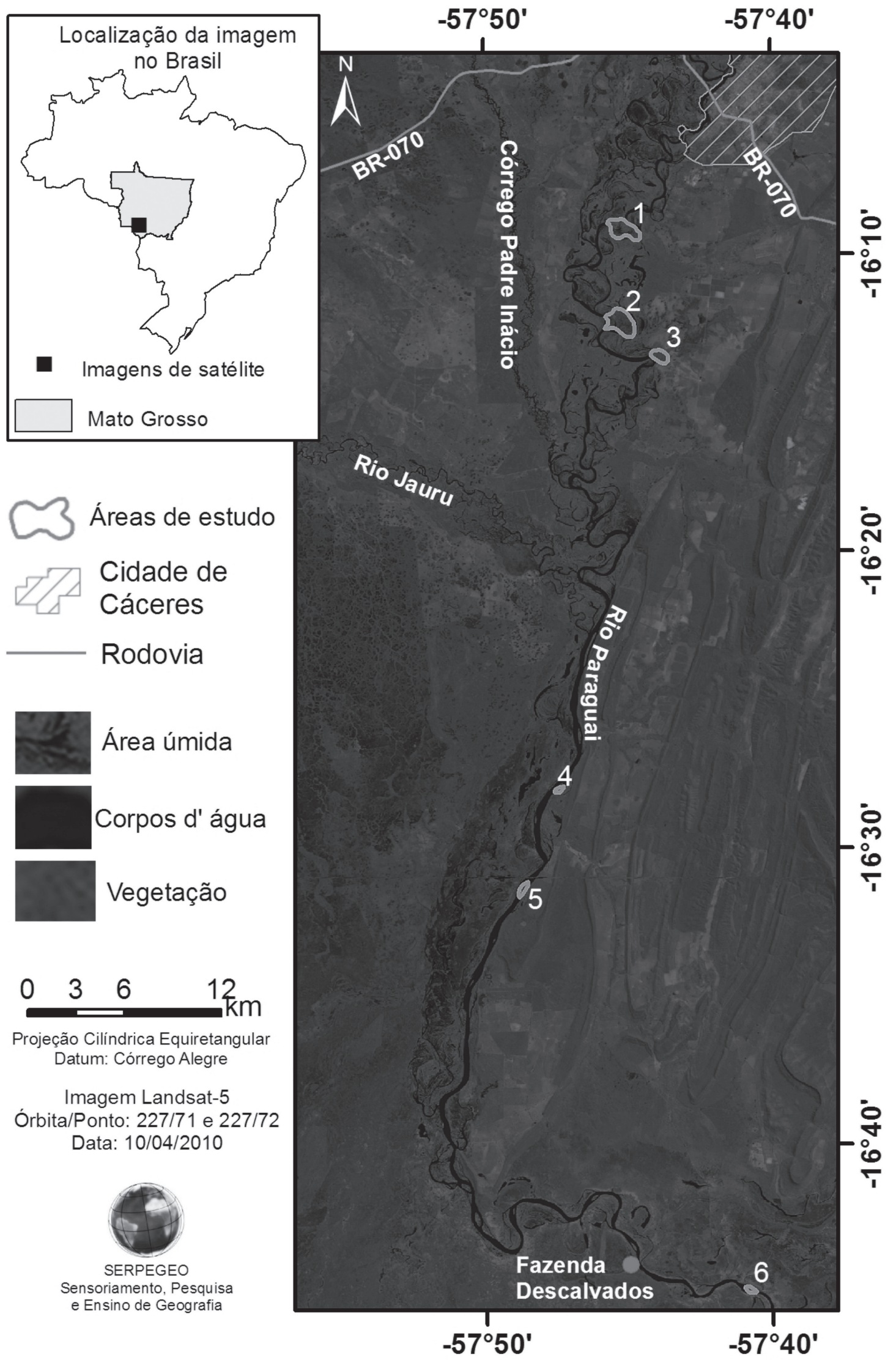

Figura 1. Área de estudo com localização das seis ilhas examinadas no rio Paraguai, Região de Cáceres, Pantanal Matogrossense, Brasil. 


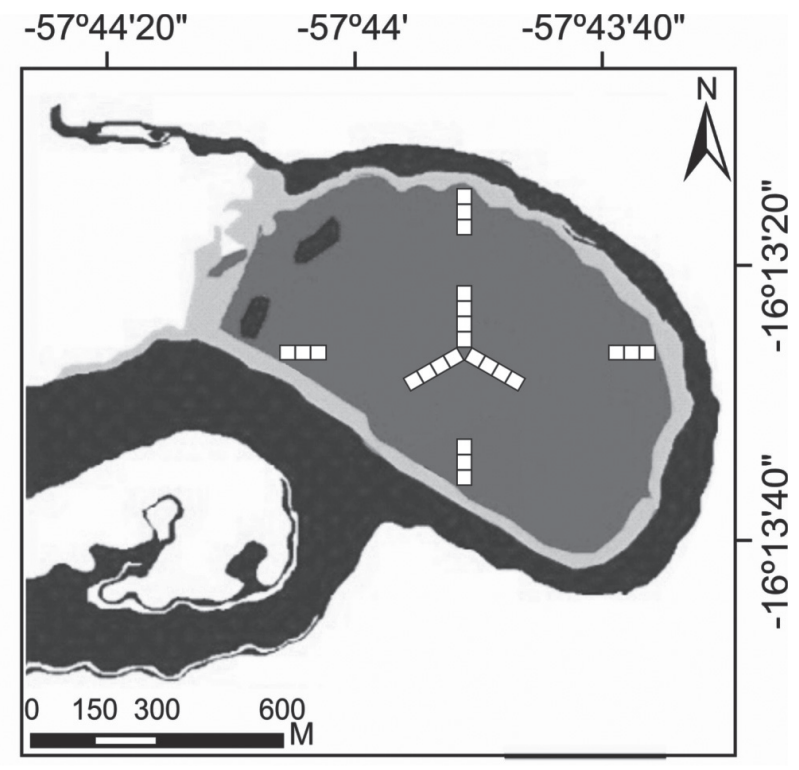

Figura 2. Área de estudo com desenho esquemático da alocação das parcelas nas ilhas do rio Paraguai, Região de Cáceres, Pantanal Matogrossense.

O teste de Mantel foi utilizado para testar a presença de auto-correlação espacial entre as variáveis dependentes (representada pela matriz de similaridade florística de Sorensen) e independentes (distância geográfica euclidiana entre unidades amostrais). As análises foram gerados com o pacote estatístico R (R Development Core Team 2010).

\section{Resultados e discussão}

\section{Estrutura e Composição florística}

Nas seis ilhas do rio Paraguai, foram encontradas 40 espécies distribuídas em 34 gêneros e 21 famílias. A espécie mais abundante foi Sapium obovatum, contribuindo com $40,79 \%$ dos indivíduos, seguida por Laetia americana $(9,02$ $\%)$, Psidium nutans (6,7\%), Zygia inaequalis (6,44\%), Albizia polyantha (3,69\%) (Tab.1). As famílias mais importantes com relação ao número de espécies são: Euphorbiaceae (5), Myrtaceae (5), Fabaceae-Mimosoideae (4) e Salicaceae (3). Do total das famílias amostradas, 11 foram representadas por uma única espécie.

A curva de incremento de espécies não variou entre as ilhas, sendo que apenas na ilha um houve um acréscimo nas ultimas parcelas, entretanto o número de espécies era superior a $80 \%$ em todas as ilhas na metade da área amostral (Fig. 3).

Os maiores Valores de Importância (VI) encontrados entre as espécies foram: Sapium obovatum $(108,852)$, Laetia americana $(17,49)$, Albizia inundata $(16,25)$, Zygia inaequalis $(14,66)$ e Psidium nutans $(13,98)$ em seguida arvores mortas em pé representaram um VI de $(13,35)$. Teoricamente, as espécies mais importantes em termos de VI, são aquelas que apresentam maior sucesso em explorar os recursos de seus habitats (Felfili et al. 1998).
Os indivíduos mortos em pé neste levantamento representaram 3,43\% do número total de indivíduos. Damasceno Junior et al. (2004) realizaram um estudo em mata alagável no rio Paraguai em Corumbá, para verificar a mortalidade da vegetação após uma cheia excepcional em 1995 registrou a taxa de mortalidade total foi de $4,1 \%$, sendo maior nas faixas topográficas mais altas, indicando que lugares onde as inundações são mais raras são mais afetados pelas grandes cheias. A quantidade de indivíduos mortos em pé nas ilhas pode estar igualmente relacionada à cheia excepcional no ano de 2007 na região deste trabalho.

$\mathrm{O}$ número de espécies arbóreas que encontrado nas ilhas, está mais próximo ao número de espécies encontradas no levantamento da mata ciliar do rio Paraguai próximo a Corumbá por Damasceno Junior (2005) que encontrou 37 espécies, 35 gêneros e 23 famílias em 1,08 ha. São comuns aos dois trabalhos 13 espécies, provavelmente não existe alta similaridade devido à família Arecaceae que não foi levantada nesta pesquisa e a diferença topográfica entre as ilhas e as margens do rio. A espécie com maior valor de importância também se diferiu, sendo que é notável o alto valor de Sapium obovatum $(108,8)$ nas ilhas do Pantanal de Cáceres, diferindo da espécie com maior VI as margens do rio Paraguai em Corumbá Inga vera, igualmente com alto valor de importância (VI = 116,9).

O número de espécies deste trabalho também se assemelha ao levantamento realizado nos cerradões do Pantanal por Salis et al. (2006), que ao verificar a distribuição e abundância de espécies arbóreas em cerradões no Pantanal, registrou para as seis áreas levantadas uma elevada heterogeneidade entre os cerradões, pois os valores foram bastante variáveis como o número de espécies ( 27 a 43) entretanto ao considerar as seis áreas de estudo conjuntamente, foram encontradas 86 espécies. Outro levantamento realizado no Pantanal em um fragmento de Floresta estacional decidual em Corumbá foram levantadas 79 espécies (Salis et al. 2004).

Ambientes com condições extremas, como baixa disponibilidade de água e nutrientes ou com excesso de água e nutrientes, tendem a aumentar a dominância ecológica de algumas espécies (Ashton 1990). Neste estudo verificouse que $S$. obovatum é uma espécie dominante, de ampla ocorrência, freqüente em todas ilhas e obteve maior VI em quatro ilhas (Figura 4).

\section{Diversidade e riqueza}

O Índice de Diversidade de Shannon variou nas ilhas entre 0,91 a 2,72 (Tab. 2) apresentou valores intermediários quando comparados a outros levantamentos no Pantanal, como observado em uma mata de Vochysia divergens com o valor de 1,56 (Nascimento \& Nunes da Cunha 1989), em formações arbóreas com H’ entre 1,75 e 3,0 (Salis et al.1999) e mata inundável H’ = 2,7 (Damasceno Junior, et al. 2004). Também próximo ao H’ = 2,9 verificado por Ariela \& Nunes da Cunha (2006), realizado em um cambarazal no Pantanal. Os valores de diversidade obtidos nas ilhas sugerem baixa 
Tabela 1. Parâmetros fitossociológicos das espécies arbóreas de seis ilhas do Rio Paraguai (Parâmetros: $\mathrm{N}=$ Número de indivíduos arbóreos, $\mathrm{AB}=\mathrm{A}$ rea $\mathrm{Basal}, \mathrm{DR}=$ Densidade Relativa, FR= Freqüência Relativa, DoR= Dominância Relativa, VC= Valor de Cobertura, IVI= Índice de Valor de Importância e RHPAN= Registro no Herbário do Pantanal).

\begin{tabular}{|c|c|c|c|c|c|c|c|c|}
\hline Espécie & $\mathrm{N}$ & $\mathrm{AB}$ & DR & FR & DoR & $\mathrm{VC}$ & IVI & RHPAN \\
\hline Sapium obovatum Klotzsch ex Müll. Arg. & 773 & 30,30 & 40,79 & 16,42 & 51,65 & 92,43 & 108,85 & 158 \\
\hline Laetia americana $\mathrm{L}$. & 170 & 1,09 & 9,02 & 6,60 & 1,87 & 10,89 & 17,49 & 144 \\
\hline Albizia inundata (Mart.) Barneby \& J.W. Grimes & 70 & 2,83 & 3,69 & 7,74 & 4,83 & 8,52 & 16,25 & 166 \\
\hline Zygia inaequalis (Humb. \& Bonpl. ex Willd.) Pittier & 122 & 1,61 & 6,44 & 5,47 & 2,76 & 9,19 & 14,66 & 232 \\
\hline Psidium nutans $\mathrm{O}$. Berg & 127 & 1,61 & 6,70 & 4,53 & 2,75 & 9,45 & 13,98 & 154 \\
\hline Mortas & 65 & 1,61 & 3,43 & 7,17 & 2,76 & 6,18 & 13,35 & - \\
\hline Banara arguta Briq. & 55 & 1,41 & 2,90 & 5,85 & 2,42 & 5,32 & 11,17 & 168 \\
\hline Vochysia divergens Pohl & 25 & 4,31 & 1,32 & 2,26 & 7,36 & 8,67 & 10,94 & 146 \\
\hline Ocotea diospyrifolia (Meisn.) Mez & 45 & 1,81 & 2,48 & 4,71 & 3,09 & 5,57 & 10,29 & 155 \\
\hline Crataeva tapia $\mathrm{L}$. & 53 & 0,78 & 2,80 & 4,53 & 1,33 & 4,13 & 8,65 & 171 \\
\hline Inga vera Willd. & 38 & 2,31 & 2,00 & 2,45 & 3,94 & 5,94 & 8,39 & 156 \\
\hline Zygia latifolia (L.) Fawc. \& Rendle & 57 & 0,72 & 3,01 & 2,83 & 1,24 & 4,24 & 7,07 & 153 \\
\hline Mouriri guianensis Aubl. & 27 & 1,71 & 1,42 & 2,64 & 2,92 & 4,34 & 6,98 & 175 \\
\hline Garcinia brasiliensis Mart. & 51 & 0,29 & 2,69 & 2,64 & 0,51 & 3,20 & 5,84 & 152 \\
\hline Licania parvifolia Huber & 21 & 1,41 & 1,11 & 1,89 & 2,42 & 3,52 & 5,41 & 302 \\
\hline Trichilia catigua A. Juss. & 39 & 0,26 & 2,06 & 2,26 & 0,45 & 2,50 & 4,77 & 162 \\
\hline Swartzia jorori Harms & 10 & 1,33 & 0,53 & 1,51 & 2,27 & 2,79 & 4,30 & 303 \\
\hline Brosimum lactescens (S. Moore) C.C. Berg. & 19 & 0,76 & 1,00 & 1,70 & 1,31 & 2,31 & 4,01 & 304 \\
\hline Buchenavia oxycarpa Eichler & 16 & 0,30 & 0,84 & 2,45 & 0,53 & 1,37 & 3,82 & 305 \\
\hline Buchenavia sp. & 17 & 0,21 & 0,90 & 2,45 & 0,36 & 1,25 & 3,70 & 306 \\
\hline Pouteria glomerata (Miq.) Radlk & 17 & 0,24 & 0,90 & 1,89 & 0,41 & 1,30 & 3,19 & 169 \\
\hline Campomanesia eugenioides (Cambess.) Legrand & 14 & 0,05 & 0,74 & 1,88 & 0,10 & 0,83 & 2,72 & 165 \\
\hline Triplaris americana $\mathrm{L}$. & 14 & 0,22 & 0,74 & 1,32 & 0,38 & 1,11 & 2,43 & 170 \\
\hline Croton sellowii Baill. & 10 & 0,12 & 0,53 & 1,13 & 0,22 & 0,74 & 1,87 & 143 \\
\hline Nectandra amazonum Nees & 6 & 0,34 & 0,26 & 0,94 & 0,59 & 0,85 & 1,79 & 148 \\
\hline Ficus pertusa L. f. & 2 & 0,72 & 0,11 & 0,38 & 1,24 & 1,34 & 1,72 & 174 \\
\hline Casearia aculeata Jacq. & 10 & 0,05 & 0,52 & 0,76 & 0,09 & 0,61 & 1,37 & 150 \\
\hline Alchornea discolor Poepp. & 5 & 0,04 & 0,26 & 0,75 & 0,07 & 0,33 & 1,08 & 149 \\
\hline Myrcia cf. mollis (Kunth) DC. & 4 & 0,02 & 0,22 & 0,76 & 0,03 & 0,24 & 1,00 & 163 \\
\hline Alchornea sp. & 5 & 0,12 & 0,26 & 0,38 & 0,22 & 0,48 & 0,85 & 307 \\
\hline Byrsonima ligustrifolia A. Juss. & 3 & 0,079 & 0,16 & 0,57 & 0,13 & 0,29 & 0,85 & 151 \\
\hline Platymiscium sp. & 3 & 0,076 & 0,16 & 0,38 & 0,13 & 0,28 & 0,66 & 308 \\
\hline Spondias mombin $\mathrm{L}$. & 3 & 0,04 & 0,11 & 0,38 & 0,07 & 0,17 & 0,55 & 177 \\
\hline Myrcia sp. & 2 & 0,04 & 0,05 & 0,19 & 0,07 & 0,12 & 0,31 & 309 \\
\hline Picramnia sp. & 1 & 0,009 & 0,05 & 0,19 & 0,02 & 0,07 & 0,25 & 310 \\
\hline Coccoloba rigida Meisn. & 1 & 0,01 & 0,05 & 0,19 & 0,02 & 0,07 & 0,25 & 311 \\
\hline Licania sp. & 1 & 0,008 & 0,05 & 0,19 & 0,01 & 0,06 & 0,25 & 312 \\
\hline Alchornea castaneifolia (Wild.) A. Juss. & 1 & 0,006 & 0,05 & 0,19 & 0,01 & 0,06 & 0,25 & 313 \\
\hline Laetia sp. & 1 & 0,003 & 0,05 & 0,19 & 0,01 & 0,05 & 0,24 & 314 \\
\hline Agonandra brasiliensis Benth. \& Hook.f. & 1 & 0,003 & 0,05 & 0,19 & 0,01 & 0,05 & 0,24 & 159 \\
\hline Zizyphus oblongifolius S. Moore & 1 & 0,003 & 0,05 & 0,19 & 0,01 & 0,05 & 0,24 & 147 \\
\hline Total & 1895 & 58,68 & 100 & 100 & 100 & 200 & 300 & \\
\hline
\end{tabular}



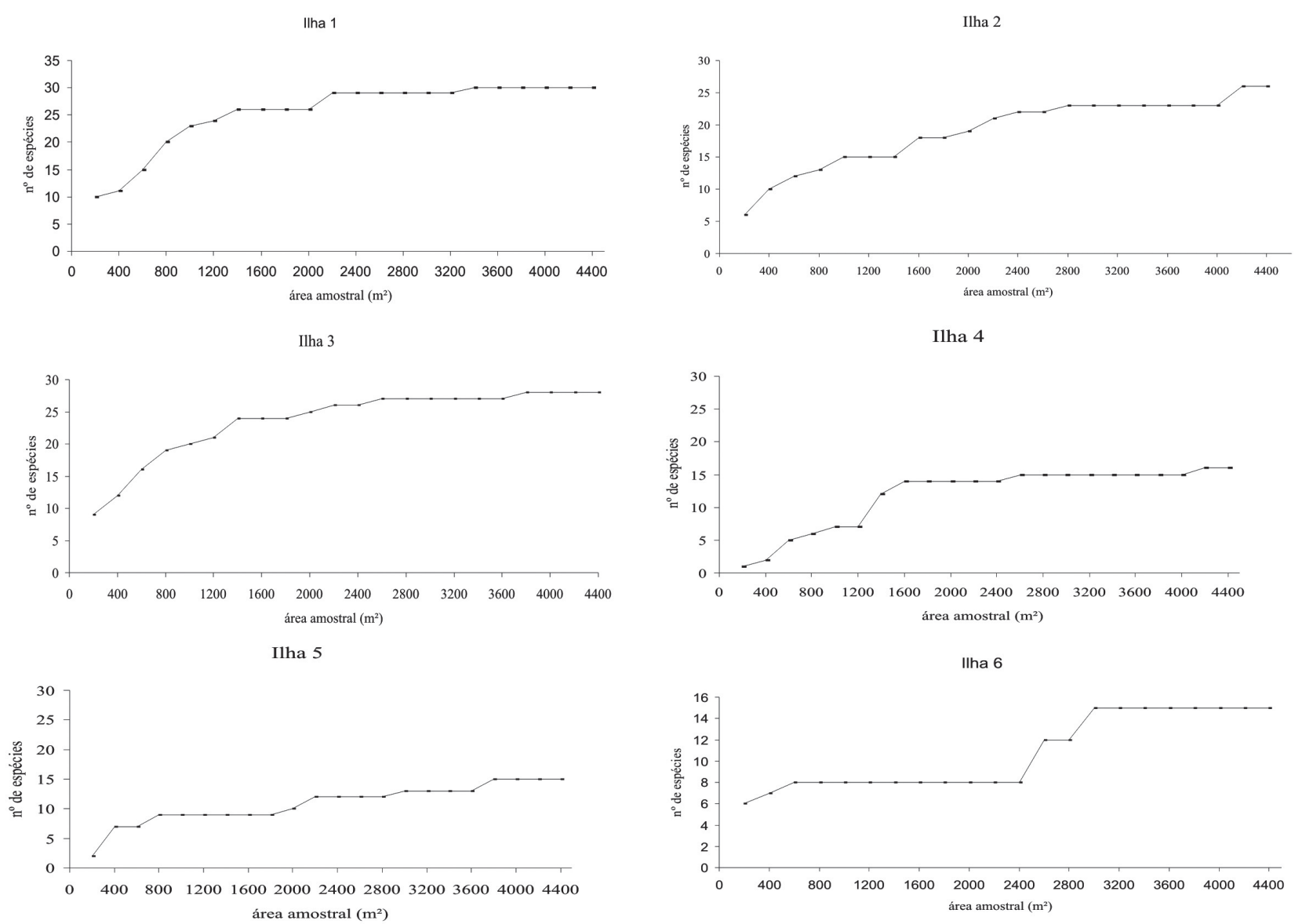

Figura 3. Número acumulado de espécies arbóreas nas parcelas amostradas nas seis ilhas do rio Paraguai, Região de Cáceres, Pantanal Matogrossense.

riqueza e diferença de densidade entre as populações, assim como em outros estudos realizados em áreas inundáveis. No pantanal diversos estudos têm enfatizado a importância do regime de inundação na distribuição das comunidades e demonstram que algumas unidades de paisagem são diretamente influenciadas pelo período de inundação que está submetido a partir da diferenciação topográfica em que se encontram (Pott \& Adámoli, 1999; Nunes da Cunha \& Junk 2001; Da Silva et al. 2001, Damasceno Júnior et al. 2005; Arieira \& Nunes da Cunha 2006).

Nas ilhas originárias do rompimento de colo de barranco o índice de diversidade foi maior que nas ilhas originárias da sedimentação, embora comparativamente com outras regiões não inundáveis sejam baixos, pois estão relacionados à dominância de determinadas populações. A ilha seis, formada por sedimentação, possui H'com valor próximo aos encontrados nas ilhas formadas por rompimento de colo de meandro, devido à alta equitabilidade. A riqueza foi significativamente diferente entre as ilhas, sendo que nas ilhas formadas por rompimento de colo de meandro (Ilhas RC= $5,8 \pm 2,9)$ foi maior que nas ilhas formadas por sedimentação $(\mathrm{IS}=2,4 \pm 1,7)($ ANOVA $\mathrm{F}=63,53 \mathrm{e} \mathrm{p} \leq 0,0001)$ (Fig. 5).

No rio Paraguai, Damasceno Junior \& Bezerra (2004) realizaram um trabalho sobre a estrutura da vegetação ilha da lagoa do Castelo em Corumbá, MS e foram encontradas 18 espécies pertencentes a 12 famílias botânicas. O índice de diversidade $\left(\mathrm{H}^{\prime}\right)$ para espécies foi de 2,21, entretanto a vegetação daquela ilha é de mata decídua, não havendo espécies em comum com este trabalho.

Neste estudo como demonstra o cluster (Fig. 6), algumas ilhas apresentaram altos índices de similaridade, por exemplo, as ilhas 1 e 2 com Índice de Sorensen $=0,89$. Houve uma divisão em dois grupos, originárias dos dois processos: a partir do rompimento do colo do meandro ilhas 1,2 e $3 \mathrm{e}$ as formadas a partir de sedimentação (ilhas 4,5 e 6 ).

Em geral as espécies foram de ampla ocorrência. $\mathrm{Sa}$ pium obovatum foi a espécie com maior freqüência nas ilhas e parcelas. 17 espécies foram exclusivas das ilhas 1,2 e 3 formadas a partir do rompimento do colo de meandro. Nas ilhas formadas a partir do processo de sedimentação foram exclusivas quatro espécies (Tab. 3). Oito espécies apareceram em apenas uma das ilhas o que contribuiu para dissimilaridade. No rio Paraná, estudos em ilhas formadas por processos de coalescência de barras, realizados por Corradini et al. (2008), observaram o controle que a geomorfologia, especificamente do relevo, exerce sobre a vegetação, verificando uma sucessão de estratos de vegetação ripária e a relação com a morfologia da superfície. 

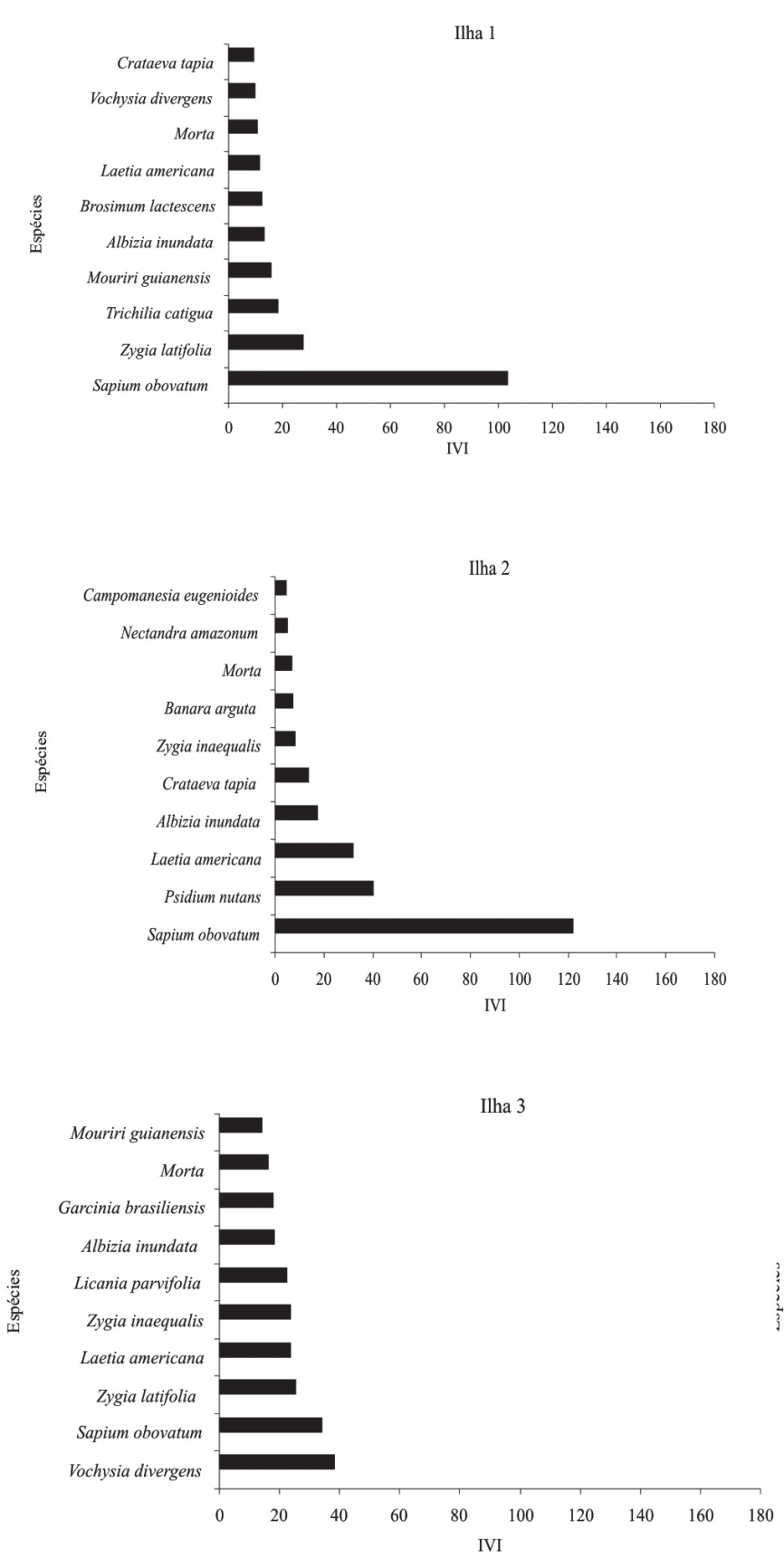
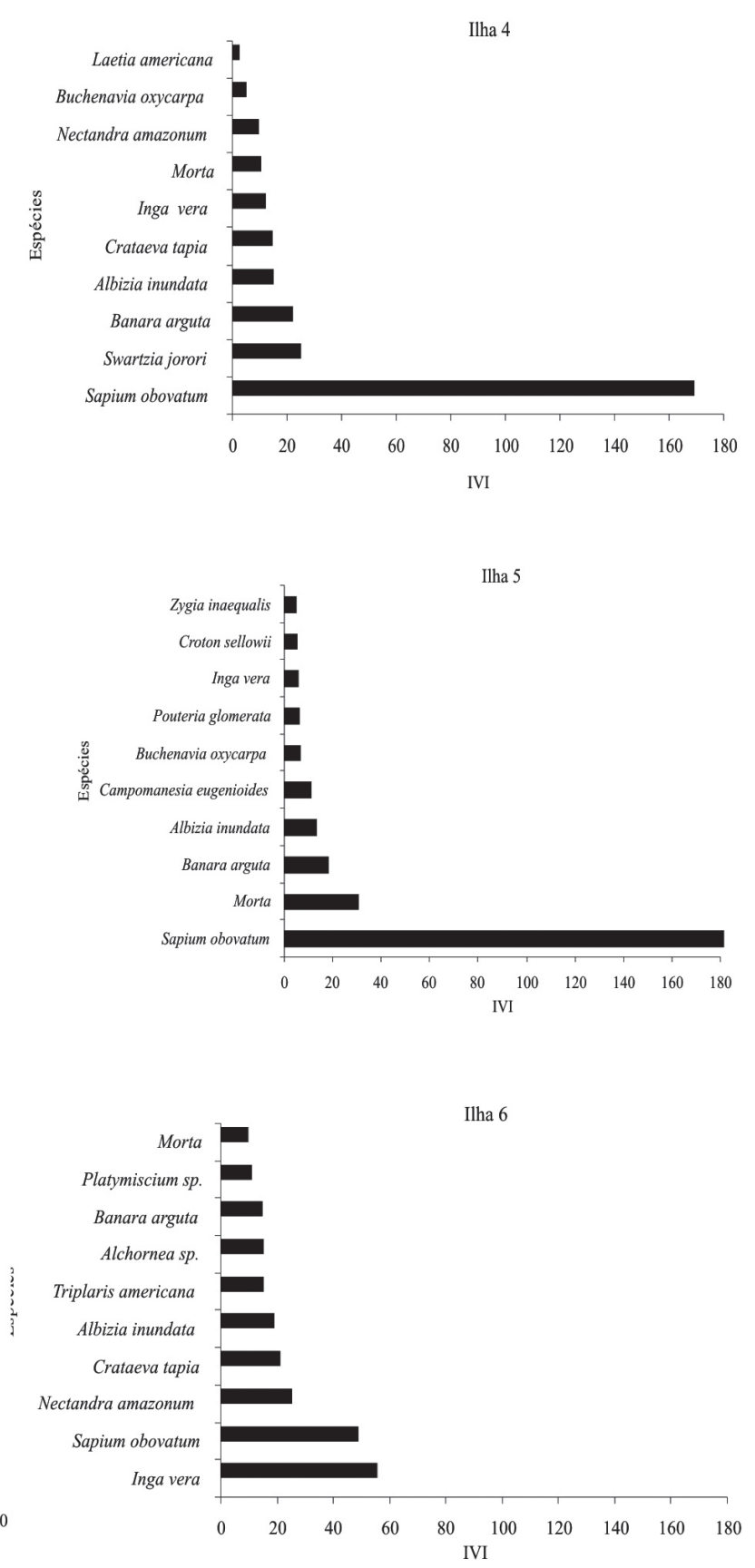

Figura 4. Espécies com Valor de Importância das para as seis ilhas, fluviais do rio Paraguai, no trecho entre Cáceres e a Estação Ecológica de Taiamã, Pantanal Matogrossense.

Houve distinção na composição de espécies entre as parcelas de centro e de borda das ilhas apenas para as ilhas formadas a partir do rompimento de colo de meandro, sendo que considerando todas as parcelas Alchornea discolor, Coccoloba sp., Croton sellowii, Myrcia sp., Picramnia sp., Spondias monbin, Triplaris americana são espécies exclusivas das bordas destas ilhas e Agonandra brasiliensis e Licania sp exclusivas do centro (Fig. 7). As ilhas formadas pelo rompimento de colo de meandro possuem diferenças na composição florística entre locais entre centro e borda, o que demonstra uma heterogeneidade de ambientes que podem estar influenciando na distribuição da vegetação arbórea destas ilhas. Variações na topografia e no solo dentro de uma região criam um mosaico de heterogeneidade de partes de habitat que formam a paisagem local. As variações hídricas do solo, vinculadas a topografia local, constituem o principal fator na base da elevada heterogeneidade das florestas de galeria (Oliveira-Filho et al. 1994).

O teste de Mantel apontou correlação entre as distâncias geográficas das ilhas e a similaridade florística (Mantel: $\mathrm{r}=$ 
Tabela 2. Ilhas ao longo do rio Paraguai com respectivo número de indivíduos $(\mathrm{N})$, número de espécies $(\mathrm{S})$, diversidade máxima (ln(S)), índice de diversidade de Shannon-Weaver (H'), intervalo de confiança de Jackknife (Jackknife) e equabilidade de Pielou (J).

\begin{tabular}{|c|c|c|c|c|c|c|}
\hline & $\mathrm{N}$ & S & $\ln (S)$ & $\mathrm{H}^{\prime}$ & Jackknife & J \\
\hline Ilha 1 & 550 & 30 & 3,40 & 2,02 & 1,69 a 2,48 & 0,59 \\
\hline Ilha 2 & 371 & 26 & 3,26 & 2,06 & 1,63 a 2,68 & 0,63 \\
\hline Ilha 3 & 420 & 28 & 3,33 & 2,72 & 2,70 a 2,97 & 0,82 \\
\hline Ilha 4 & 167 & 16 & 2,57 & 1,33 & 0,87 a 2,00 & 0,48 \\
\hline Ilha 5 & 262 & 15 & 2,71 & 0,91 & 0,38 a 1,52 & 0,34 \\
\hline Ilha 6 & 60 & 15 & 2,71 & 2,41 & 2,23 a 3,15 & 0,89 \\
\hline
\end{tabular}

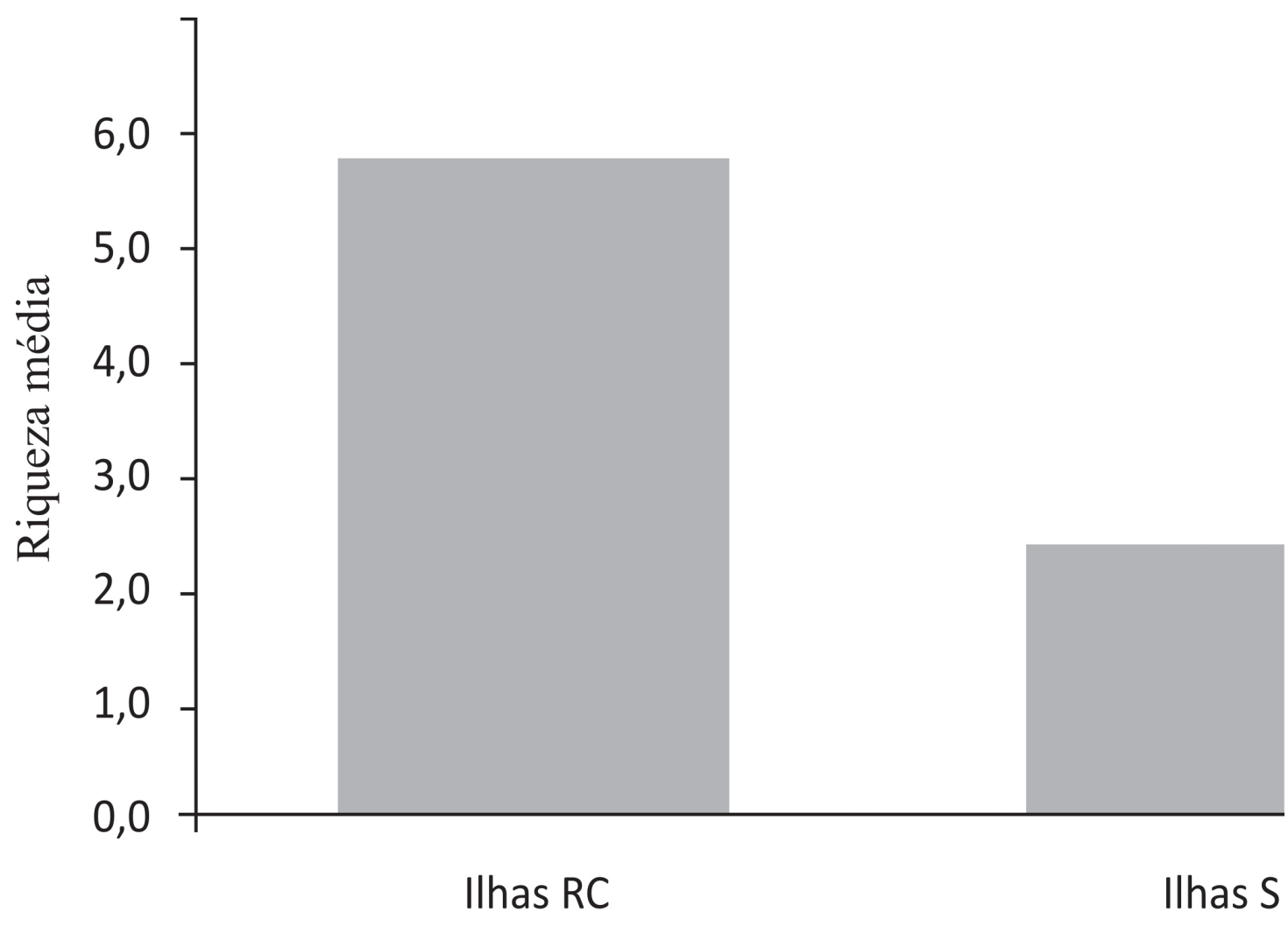

Figura 5. Comparação da riqueza entre ilhas do rio Paraguai de origem de rompimento de colo de meandro (Ilhas RC) e ilhas formadas a partir de sedimentação (Ilhas S), na região de Cáceres, Pantanal Matogrossense.

$0.6138 ; \mathrm{p}=0.0264)$, isto se deve pela proximidade geográfica de ilhas com a mesma formação e com alta similaridade florística. Puhakka et al. (1993) estudando a sucessão florestal que segue a migração de rios na baixa selva peruana, sugerem que devido aos bosques ribeirinhos sucessionais apresentarem uma origem geomorfológica comum, habitats similares se repetem ao longo dos cursos dos rios. Por esta razão, sugerem a importância de se estudar a similaridade das comunidades de plantas próximas a cursos de rios. Alguns autores tem verificado que a perturbação pelo fluxo dos rios e erosão dos sedimentos e deposição influencia os padrões de vegetação ciliar, resultando na associação estreita entre a composição da vegetação e da idade e as características geomorfológicas (Rozenblit et al. 2007).
Neste estudo verificou-se que a maior diversidade, riqueza e abundancia esta relacionada às ilhas formadas por rompimento de colo de meandro que possuem áreas maiores. A maior diversidade, riqueza e abundância pode ser justificada por Wantzen et al. (2005) que realizaram um levantamento de habitats ao longo do rio Paraguai a Estação Ecológica de Taiamã e sugerem que em meandros e setores de transição, como no caso da localização destas três ilhas, ocorre maior diversidade de unidades funcionais, que pode estar refletindo na diversidade das espécies e nos padrões de distribuição.

São múltiplos os fatores que estão atuando conjuntamente nas ilhas do Pantanal contribuindo para a diversidade arbórea atual. Para detectar o mecanismo de manutenção das 
Tabela 3. Lista de famílias e espécies presentes nas ilhas ao longo do rio Paraguai. Região de Cáceres, Pantanal Matogrossense, Brasil.

\begin{tabular}{|c|c|c|c|c|c|c|c|}
\hline \multirow{2}{*}{ Família } & \multirow{2}{*}{ Espécie } & \multicolumn{6}{|c|}{ Ilhas } \\
\hline & & 1 & 2 & 3 & 4 & 5 & 6 \\
\hline Anacardiaceae & Spondias monbin $\mathrm{L}$. & $\mathrm{X}$ & $\mathrm{X}$ & $\mathrm{X}$ & & & \\
\hline Capparaceae & Crataeva tapia $\mathrm{L}$. & $\mathrm{X}$ & $\mathrm{X}$ & $\mathrm{X}$ & $\mathrm{x}$ & & $\mathrm{X}$ \\
\hline Combrataceae & Buchenavia oxycarpa Eichler & $\mathrm{X}$ & $\mathrm{X}$ & $\mathrm{X}$ & $\mathrm{x}$ & $\mathrm{X}$ & \\
\hline Combrataceae & Buchenavia sp. & $\mathrm{X}$ & $\mathrm{X}$ & $\mathrm{X}$ & & & \\
\hline Clusiaceae & Garcinia brasiliensis Mart. & $\mathrm{X}$ & $\mathrm{X}$ & $\mathrm{X}$ & & & \\
\hline Chysobalanaceae & Licania parvifolia Huber & $\mathrm{X}$ & $\mathrm{X}$ & $\mathrm{X}$ & & & \\
\hline Chysobalanaceae & Licania sp. & & & $\mathrm{X}$ & & & \\
\hline Euphorbiaceae & Alchornea castaneifolia (Wild.) A. Juss. & & & & & $\mathrm{X}$ & \\
\hline Euphorbiaceae & Alchornea discolor Poepp. & $\mathrm{X}$ & $\mathrm{X}$ & & & & \\
\hline Euphorbiaceae & Alchornea sp. & & & & & $\mathrm{X}$ & $\mathrm{X}$ \\
\hline Euphorbiaceae & Croton sellowii Baill. & $\mathrm{X}$ & & $\mathrm{X}$ & $\mathrm{X}$ & $\mathrm{X}$ & $\mathrm{X}$ \\
\hline Euphorbiaceae & Sapium obovatum Klotzsch ex Müll. Arg. & $\mathrm{X}$ & $\mathrm{X}$ & $\mathrm{X}$ & $\mathrm{x}$ & $\mathrm{X}$ & $\mathrm{X}$ \\
\hline Fabaceae-Faboideae & Swartzia jorori Harms & & & $\mathrm{X}$ & $\mathrm{x}$ & & \\
\hline Fabaceae-Faboideae & Platymiscium sp. & & & & & & $\mathrm{X}$ \\
\hline Salicaceae & Banara arguta Briq. & $\mathrm{X}$ & $\mathrm{X}$ & $\mathrm{X}$ & $\mathrm{X}$ & $\mathrm{X}$ & $\mathrm{X}$ \\
\hline Salicaceae & Laetia americana $\mathrm{L}$. & $\mathrm{X}$ & $\mathrm{X}$ & $\mathrm{X}$ & $\mathrm{X}$ & & \\
\hline Salicaceae & Laetia sp. & $\mathrm{X}$ & & $\mathrm{X}$ & & & \\
\hline Salicaceae & Casearia aculeata Jacq & $\mathrm{X}$ & $\mathrm{X}$ & $\mathrm{X}$ & & & \\
\hline Lauraceae & Ocotea diospyrifolia (Meisn.) Mez & $\mathrm{X}$ & $\mathrm{X}$ & $\mathrm{X}$ & & & \\
\hline Lauraceae & Nectandra amazonum Nees & $\mathrm{X}$ & $\mathrm{X}$ & $\mathrm{X}$ & $\mathrm{X}$ & & $\mathrm{X}$ \\
\hline Malpighiaceae & Byrsonima ligustrifolia A. Juss. & $\mathrm{X}$ & $\mathrm{X}$ & & & & \\
\hline Melastomataceae & Mouriri guianensis Aubl. & $\mathrm{X}$ & $\mathrm{X}$ & $\mathrm{X}$ & & & $\mathrm{X}$ \\
\hline Meliaceae & Trichilia catigua A. Juss. & $\mathrm{X}$ & $\mathrm{X}$ & $\mathrm{X}$ & & $\mathrm{X}$ & \\
\hline Fabaceae-Mimosoideae & Albizia inundata (Mart.) Barneby \& J.W. Grimes & $\mathrm{X}$ & $\mathrm{X}$ & $\mathrm{X}$ & $\mathrm{x}$ & $\mathrm{X}$ & $\mathrm{X}$ \\
\hline Fabaceae-Mimosoideae & Inga vera Willd. & $\mathrm{X}$ & $\mathrm{X}$ & $\mathrm{X}$ & $\mathrm{X}$ & $\mathrm{X}$ & $\mathrm{X}$ \\
\hline Fabaceae-Mimosoideae & Zygia inaequalis (Humb. \& Bonpl. ex Willd.) Pittier & $\mathrm{X}$ & $\mathrm{X}$ & $\mathrm{X}$ & $\mathrm{X}$ & $\mathrm{X}$ & $\mathrm{X}$ \\
\hline Fabaceae-Mimosoideae & Zygia inaequalis (Humb. \& Bonpl. ex Willd.) Pittier & $\mathrm{X}$ & $\mathrm{X}$ & $\mathrm{X}$ & & & \\
\hline Moraceae & Brosimum lactescens (S. Moore) C.C. Berg. & $\mathrm{X}$ & $\mathrm{X}$ & & $\mathrm{x}$ & $\mathrm{X}$ & $\mathrm{X}$ \\
\hline Moraceae & Ficus pertusa L. F. & & & $\mathrm{X}$ & & & \\
\hline Myrtaceae & Campomanesia eugenioides (Cambess.) Legrand & & $\mathrm{X}$ & & $\mathrm{X}$ & $\mathrm{X}$ & $\mathrm{X}$ \\
\hline Myrtaceae & Myrcia cf. mollis (Kunth) DC. & $\mathrm{X}$ & & & $\mathrm{x}$ & & $\mathrm{X}$ \\
\hline Myrtaceae & Myrcia sp. & & & $\mathrm{X}$ & & $\mathrm{X}$ & \\
\hline Myrtaceae & Psidium nutans O. Berg & $\mathrm{X}$ & $\mathrm{X}$ & $\mathrm{X}$ & & & \\
\hline Opiliaceae & Agonandra brasiliensis Benth. \& Hook.f. & & & & $\mathrm{x}$ & & \\
\hline Polygonaceae & Coccoloba rígida Meisn. & $\mathrm{X}$ & & & & & \\
\hline Polygonaceae & Triplaris americana $\mathrm{L}$. & $\mathrm{X}$ & & $\mathrm{X}$ & $\mathrm{x}$ & $\mathrm{X}$ & $\mathrm{X}$ \\
\hline Rhamnaceae & Zizyphus oblongifolius S. Moore & $\mathrm{X}$ & & & & & \\
\hline Sapotaceae & Pouteria glomerata (Miq.) Radlk & $\mathrm{X}$ & $\mathrm{X}$ & $\mathrm{X}$ & & $\mathrm{X}$ & \\
\hline Simaroubaceae. & Picramnia sp. & $\mathrm{X}$ & & & & & \\
\hline \multirow[t]{2}{*}{ Vochysiaceae } & Vochysia divergens Pohl & $\mathrm{X}$ & $\mathrm{X}$ & $X$ & & & \\
\hline & Mortas & $\mathrm{X}$ & $\mathrm{X}$ & $\mathrm{X}$ & $\mathrm{X}$ & $\mathrm{X}$ & $\mathrm{X}$ \\
\hline
\end{tabular}



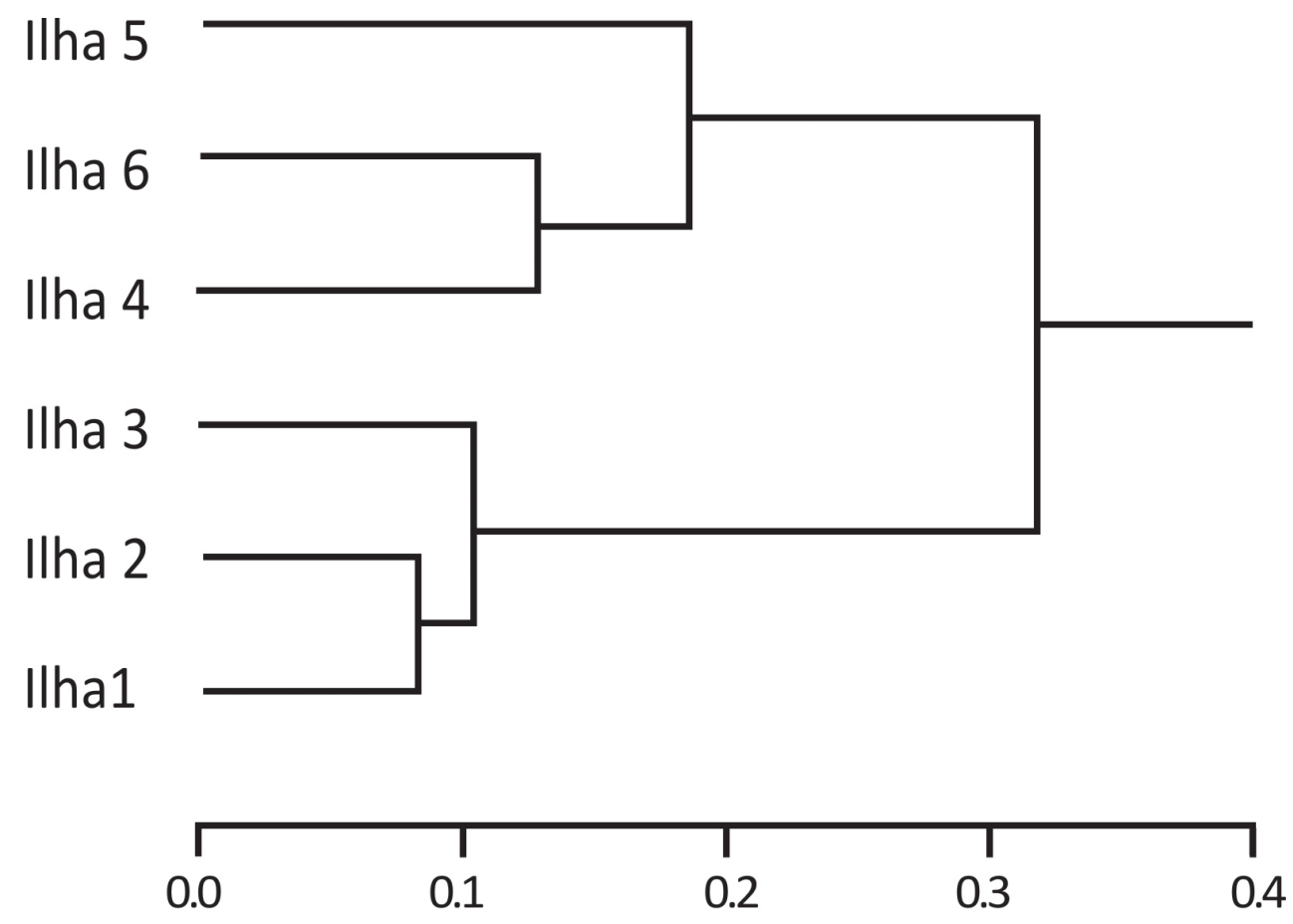

Distância

Figura 6. Cluster UPGMA - Dendrograma com ligação simples distancia euclidiana, distingue pelo coeficiente de Sorensen a diferença de espécies entre as ilhas.

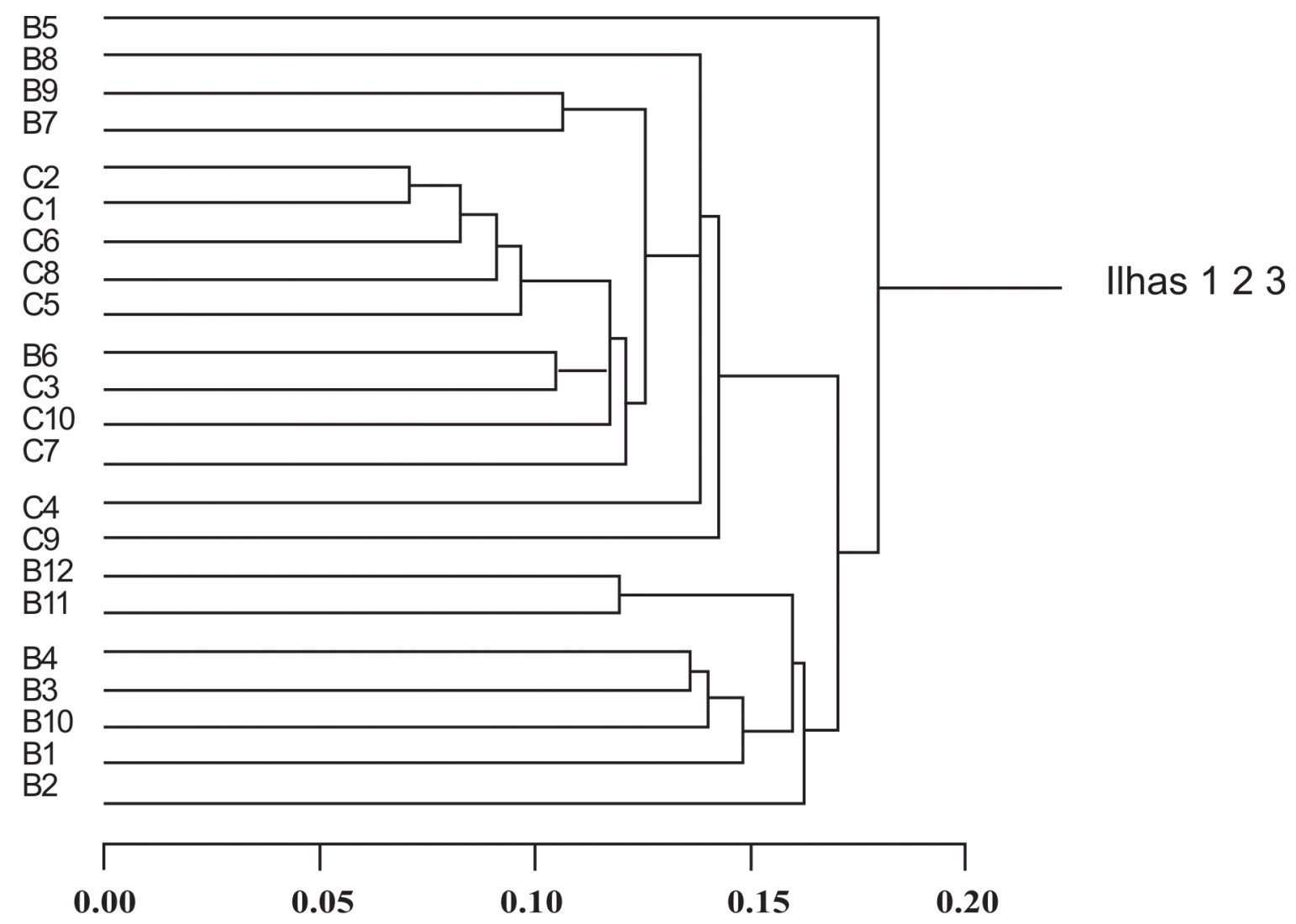

Figura 7. Cluster UPGMA - Dendrograma com ligação simples, distancia Euclidiana, distingue pelo coeficiente de Sorensen a diferença de espécies entre os locais de centro (C) e borda (B) das ilhas formadas a partir de rompimento de colo de meandro. 
comunidades nas ilhas, é necessário um acompanhamento de longo prazo através de monitoramento para determinar se os indivíduos estabelecidos estão se mantendo ou se ocorre uma renovação contínua dos indivíduos.

Segundo Silva et al. (2008), todo o segmento entre a cidade de Cáceres e Estação Ecológica de Taiamã está em processo de ajuste fluvial, desencadeado por provável aumento no aporte de sedimentos arenosos, ruptura do equilíbrio do sistema aparentemente foi causada pelo aporte excessivo de areia, cuja origem pode ser conseqüência de mudança climática ou da ocupação da bacia, ou ainda ter participação de ambos os fatores. Em relação às comunidades arbóreas estudadas ao longo do rio Paraguai os impactos causados na bacia podem colocar em risco a diversidade local, sendo importante considerar o estudo de Franz et al. (2009) que sugerem que os padrões de distribuição e ecologia de endemismos diferem consideravelmente de padrões de biodiversidade global e deve ser tratada adequadamente em estratégias de conservação. Nicho de pequenas amplitudes e as exigências específicas do habitat de endemismos de distribuição muito localizada tornam estas comunidades altamente vulneráveis às alterações climáticas.

\section{Agradecimentos}

À Universidade Federal de São Carlos (UFSCar), Universidade do Estado de Mato Grosso (UNEMAT) e Fundação de Amparo a Pesquisa de Mato Grosso (FAPEMAT) pelo apoio logístico e financiamento. Aos pesquisadores Jeanine Felfili (in memorian), Manoel Cláudio Silva Junior, José Eduardo dos Santos, Luis Eduardo Moschini, Elisabete Zanin, Yuri Tavares Rocha, Temilze Duarte, Sandra Neves e Wilkison Lopes pelos comentários a esta pesquisa. Pela contribuição na identificação das espécies agradecemos à Maria Antonia Carnielo, curadora do HPAN (Herbário do Pantanal) da Universidade do Estado de Mato Grosso aos pesquisadores Arnildo Pott, Vali Pott e Geraldo Damasceno Júnior da Universidade Federal de Mato Grosso do Sul e Libério Amorim Neto, técnico do Herbário Central da Universidade Federal de Mato Grosso.

\section{Referências bibliográficas}

Ab'Saber, A. 1988. O Pantanal Mato-Grossense e a teoria dos refúgios. Revista Brasileira de Geografia 50(2): 9-57.

Ab'Saber, A. 2006. Brasil: Paisagens de Exceção. O litoral e o Pantanal Mato- Grossense. Patrimônios Básicos. Cotia, Ateliê Editorial.

Adámoli, J.A. 1982. O Pantanal e suas relações fitogeográficas com os Cerrados; discussão sobre o conceito de complexo do Pantanal. Pp. 109-119. In: Congresso Nacional da Sociedade de Botânica do Brasil. Anais. Teresina, Universidade Federal do Piauí.

Adámoli, J.A. 1986. Fitogeografia do Pantanal, Pp. 105-106. In: Anais do $1^{\circ}$ Simpósio sobre recursos naturais e sócio-econômicos do Pantanal. Brasília, Embrapa.

Adámoli, J.A. \& Pott, A. 1999. Estudo fitossociológico e ecológico do Pantanal dos Paiaguás. Pp. 215-225. In: Dantas, M.; Catto, J.B.; Resende, E.K. (Eds.). Anais do II Simpósio sobre recursos naturais e sócio-econômicos do Pantanal: manejo e conservação. Corumbá, Embrapa Pantanal.

Angiosperm Phylogeny Group (APG III). 2009. An update of the Angiosperm Phylogeny Group classification for the orders and families of fl owering plants: APG III. Botanical Journal of the Linnean Society 161: 105-121.

Arieira, J. \& Nunes da Cunha, C. 2006. Fitossociologia de uma floresta inundável monodominante de Vochysia divergens Pohl. (Vochysiaceae), no Pantanal Norte, Mato Grosso (Brasil). Acta Botanica Brasilica 20: 269-280.

Ashton, P.S. 1990. Species richness in tropical forests. Pp. 239-251. In: Holm-Nielsen, L.B.; Nielsen, I.C. \& Balslev, H. (Eds.). Tropical Forests - Botanical dynamics, speciation and diversity. London, Academic Press.

Ayres, M.; Ayres Jr.M.; Ayres, D.L. \& Santos, A.S. 2007. BioEstat 5.0: aplicações estatísticas nas áreas das ciências biológicas e médicas. Brasília, CNPq/Conservation International, Manual do programa Bioestat

Brose, U. 2001. Relative importance of isolation, area and habitat heterogeneity for vascular plant species richness of temporary wetlands in east-German farmland. Ecography 24: 722-730.

CIENTEC - Consultoria e Desenvolvimento de Sistemas. 2006. Mata Nativa 2, versão 2: Sistema para análise fitossociológica e elaboração de inventários e planos de manejo de florestas nativas. Viçosa, Cientec.

Corradini, F.A.; Stevaux, J.C. \& Fachini, M.P. 2008. Geomorfologia e distribuição da vegetação ripária na ilha mutum, rio Paraná - PR/MS. Geociências 27(3): 345-354.

Da Silva, C.J.; Wantzen, K.M.; Nunes da Cunha, C. \& Machado, F.A. 2001. Biodiversity in the Pantanal Wetland, Brazil. Pp. 187-215. In: Biodiversity in wetlands: assessment, function and conservation, volume 2. Leiden. Gopal, B.; Junk, W.J. \& Davis, J.A. Backhuys Publishers.

Damasceno-Júnior, G.A.; Bezerra, M.A.O.; Bortolotto, I.M. \& Pott, A. 1999. Aspectos florísticos e fitosionômicos dos capões do Pantanal do Abobral. Pp. 203-214. In: Dantas, M.; Catto, J.B. \& Resende, E.K. (Eds.). Anais do II Simpósio sobre recursos naturais e sócio-econômicos do Pantanal: manejo e conservação.Corumbá, Embrapa Pantanal.

Damasceno-Junior, G.A. \& Bezerra, M.A.O. 2004. Estudo Fitossociológico em uma Ilha Fluvial na Lagoa do Castelo, Pantanal, Corumbá, MS. In: IV Simpósio sobre recursos naturais e Sócio-Econômicos do Pantanal: Sustentabilidade Regional, 2004, Corumbá. Anais do IV Simpósio sobre recursos naturais e Sócio-Econômicos do Pantanal: Sustentabilidade Regional. Corumbá, Embrapa Pantanal.

Damasceno-Junior, G.A.; Semir, J.; Santos, F.A.M. \& Leitão-Filho, H.F. 2004. Tree mortality in a riparian forest at Rio Paraguai, Pantanal, Brazil, after an extreme flooding. Acta Botanica Brasilica 18(4): 839-846.

Damasceno-Junior, G.A.; Semir,J.; Santos, F.A.M.-\& Leitão-Filho, H.F. 2005. Structure, distribution of species and inundation in a riparian forest of Rio Paraguai, Pantanal, Brazil. Flora (Jena) 200(2): 119-135.

Felfili, J.M.; Silva Júnior, M.C. \& Nogueira, P.E. 1998. Levantamento da vegetação arbórea na região de Nova Xavantina, MT. Bol. Herb. Ezechias Paulo Heringer 3: 63-81.

Franco, M. do S.M. \& Pinheiro, R. 1982. Geomorfologia. Pp. 161-224. In: Projeto RADAMBRASIL. Folha SE 21 Corumbá. Levantamento de recursos naturais. Rio de Janeiro, MME.

Franz, E.; Staudinger M.; Stohr, O.; Schratt-Ehrendorfer, L.; Rabitsch, W. \& Niklfeld, H. 2009. Distribution patterns, range size and niche breadth of Austrian endemic plants. Biological Conservation 142(19): 2547-2558.

Hamilton, S.K.; Sippel S.J. \& Melack, J.M. 1996. Inundation patterns in the Pantanal wetland of South America determined from passive microwave remote sensing. Arch. Hidrobiol 131(1): 1-23

Heltshe, J.F. \& Forrester, N.E. 1983. Estimating species richness using the jackknife procedure. Biometrics 39: 1-11.

Ikeda-Castrillon, S.K.; Da Silva, C.J.; Fernandez, J.R.C.; Neves, R. \& Leite, I. 2011. Assessment of the arboreal species diversity and correlation between the species distribution and soil characteristics among Paraguay River islands, section between Caceres and Taimã Ecological Station, Pantanal, Brazil. Geografia 36(Número Especial): 119-134. 
James, F.C. \& McCulloch, C.E. 1990. Multivariate analysis in ecology and systematics: Panacea or Pandora's box. Annual Review of Ecology and Systematics 21: 129-166.

Junk, W.J.; Bayley, P.B. \& Sparks, R.E. 1989. The flood pulse concept in river-floodplain. Can. Spec. Plubl. Fisheries and Aquatic Science 106: 110-127.

Junk, W.J. \& Da Silva, C.J. 1999. O conceito do pulso de inundação e suas implicações para o Pantanal de Mato Grosso. Pp. 17-28. In: Dantas, M.; Catto, J.B. \& Resende, E.K. (Eds.). Anais do II Simpósio sobre recursos naturais e sócio-econômicos do Pantanal: manejo e conservação. Corumbá, Embrapa Pantanal.

Kent, M. \& Coker, P. 1996. Vegetation description and analysis: a practical approach. London, Belhaven Press.

MacArthur, R.H. \&Wilson, E.O. 1967. The theory of island biogeography. Princeton, Oxford University Press.

Muller-Dombois, D. \& Ellenberg, H. 1974. Aims and Methods of vegetation ecology, New York, Wiley International.

Nascimento, M.T. \& Nunes da Cunha, C. 1989. Estrutura e composição florística de um cambarazal no Pantanal de Poconé-MT. Acta Botanica Brasilica 3(1): 3-23.

Nunes da Cunha, C. \& Junk, W.J. 1999. Composição florística de capões e cordilheiras: localização das espécies lenhosas quanto ao gradiente de inundação no Pantanal de Poconé, MT- Brasil. Pp. 387-405. In: Dantas, M.; Catto, J.B. \& Resende, E.K. (Eds.). Anais do II Simpósio sobre recursos naturais e sócio-econômicos do Pantanal: manejo e conservação. Corumbá, Embrapa Pantanal.

Nunes da Cunha, C. \& Junk, W.J. 2001. Distribution of wood plant communities along the flood gradient in the Pantanal of Poconé, Mato Grosso, Brazil. International Journal of Ecology and Environmental 27: 63-70.

Oliveira-Filho, A.T.; Vilela, E.A.; Carvalho, D.A. \& Gavilanes, M.L. 1994. Effects of soils and topography on the distribution of tree species in a tropical riverine forest in south-eastern Brazil. Journal of Tropical Ecology 10: 483-508.

PCBAP. 1997. Plano de Conservação da Bacia do Alto Paraguai (Pantanal). Análise integrada e prognóstico da Bacia do Alto Paraguai. vol 3. Brasília, Ministério do Meio Ambiente, dos Recursos hídricos e da Amazônia Legal. Programa Nacional do Meio Ambiente. Brasília, PNMA.

Pott A. \& Adámoli J. 1999. Unidades vegetais do Pantanal do Paiaguás. Pp. 183-202. In: Anais do II Simpósio sobre recursos naturais e sócio-econômicos do Pantanal: manejo e conservação. Corumbá, Embrapa Pantanal.

Prance, G.T. \& Schaller, G.B. 1982. Preliminary study of some vegetation types of the Pantanal, Mato grosso, Brazil. Brittonia 34: 228-251.

Puhakka, M.; Kalliola, R.; Salo, J. \& Rajasilta, M. 1993. La sucesión forsetal que sigue a la migración de ríos en la selva baja peruana. Pp. 113-138. In: Kalliola, R.; Puhakka,M. \& Danjoy, W. (Eds.). Amazonia Peruana: vegetación húmeda tropical en el llano subandino. Turku, Proyecto
Amazonia/Universidad de Turku y Oficina Nacional de Evaluación de Recursos Naturales.

R Development Core Team, 2009. R: A languagend environment for statistical computing. R Foundation for Statistical Computing, Vienna, Austria. ISBN 3-900051-07-0, URL http://www.Rproject.org.

Rozenblit, D.; Steiger, J.; Gurnel, A. \& Naiman, R. 2007. Plants intertwine fluvial landform dynamics with ecological succession and natural selection: a niche construction perspective for riparian systems Global Ecology \& Biogeography 18(4): 507-520.

Salis, M.S.; Pott V.J. \& Pott A. 1999. Fitossociologia das formações arbóreas da bacia do Alto Paraguai, Brasil. Pp. 357-373. In: Dantas, M.; Catto, J.B. \& Resende, E.K. (Eds.). Anais do II Simpósio sobre recursos naturais e sócio-econômicos do Pantanal: manejo e conservação. Corumbá, Embrapa Pantanal,

Salis, S.M.; Assis, M.A.; Da Silva, M.P.; Mattos, P.P.; Silva J.V.; Pott, V.J. \& Pott, A. 2004. Fitossociologia de remanescentes de floresta estacional decidual em Corumbá, Estado do Mato Grosso do Sul, Brasil. Revista Brasileira de Botânica 27(4): 671-684.

Salis S.M.; Assis M.A.; Crispim S.M.A. \&Casa-Grande J.C. 2006. Distribuição e abundância de espécies arbóreas em cerradões no Pantanal, Estado de Mato Grosso do Sul, Brasil. Revista Brasileira de Botânica 29(3): 339-352.

Silva A.; Souza-Filho E.E. \& Cunha S.B. 2008. Padrões de canal do rio Paraguai na região de Cáceres (MT). Revista Brasileira de Geociências 38(1): 167-177.

Soares, A.F.; Silva, J.S.V. \& Ferrari, D.L. 2006. Solo da paisagem do Pantanal brasileiro adequação para o atual sistema de classificação. Pp. 275-284. In: Simpósio de Geotecnologias no Pantanal, 1. Campo Grande. Simpósio de Geotecnologias no Pantanal, 1. Campinas, Embrapa Informática Agropecuária.

Souza, J.; Espírito-Santo, F.; Fontes, M.; Oliveira Filho, A. \& Botezelli, L. 2003. Análise das variações florísticas e estruturais da comunidade arbórea de um fragmento de Floresta Semidecídua às margens do rio Capivari, Lavras-MG. Revista Árvore 27(2): 185-206.

Souza, C.A. \& Cunha S.B. 2007. Pantanal de Cáceres - MT: Dinâmica das Margens do Rio Paraguai. Seção Três Lagoas. Revista Eletrônica da Associação dos Geógrafos Brasileiros IV: 18-41.

Veloso, H.P.; Rangel-Filho, A.L.T. \& Lima, J.C.A. 1991. Classificação da vegetação brasileira adaptada a um sistema universal. Rio de Janeiro, IBGE.

Triantis K.A.; Nogue's-Bravo D.; Hortal. J.; Borges, P.A.V.; Adsersen H.; Fernandez-Palacios J.M; Araújo, M.B. \& Whittaker R. J. 2008. Measurements of area and the (island) species-area relationship: new directions for an old pattern. Oikos 117: 1555-1559.

Wantzen, K.M.; Drago, E. \& Da Silva, C.J.2005. Aquatic habitats of Upper Paraguai Riverfloodplain-system and parts of the Pantanal (Brazil). Ecohydrology \& Hydrobiology 6(2): 107-126. 